\title{
Electricity Pricing and Market Power: Evidence from the Hungarian Balancing Energy Market
}

\author{
László Paizs ${ }^{1}$
}

\begin{abstract}
This paper presents an empirical analysis of the relationship between market structure and energy prices in the Hungarian balancing energy market. In Hungary, balancing energy is procured in two phases: firstly a reserve capacity auction is organized to select the generation capacities that are kept in reserve and available to the TSO in a specific day, and then a balancing energy auction is used to determine the dispatch order of reserved capacities in the hours of that day. Under this arrangement the winners of the reserve auctions and thereby the bidders in the balancing energy auctions change significantly form one day to the next. I exploit this variation in the bidding environment in the balancing energy auctions to identify the effect of market structure on prices. My empirical analysis focuses on the downward balancing market where generators submit bids for purchasing energy from the TSO. Consistently with the theoretical results in Fabra, von der Fehr, and Harbord [1], I find that the average purchasing price is positively affected by the number of bidders and the symmetry in capacity share distribution.
\end{abstract}

\section{Keywords}

decremental balancing energy, market power, multiunit auction, Hungary

\footnotetext{
${ }^{1}$ Institute of Economics, Research Centre for Economic and Regional Studies of the Hungarian Academy of Sciences H-1112 Budapest, Budaörsi 45, Hungary (e-mail: paizs.laszlo@krtk.mta.hu)
}

\section{Introduction}

Wholesale electricity markets have a number of characteristics that make them susceptible to the exercise of market power (e.g., transmission constraints, high entry barriers, price-inelastic demand, etc.). The markets for reserve capacity and balancing energy are even more susceptible to market power problems due to restrictions on foreign suppliers' participation. This paper investigates market power in the Hungarian decremental balancing energy market, motivated by the following observations. First, the auction market for decremental balancing energy in Hungary is characterized by high concentration. The average number of bidders in the daily auctions was 2.3 in 2012. Second, the hourly average price of all submitted decremental balancing energy bids was on average 5.7 EUR/MWh in 2012. Considering that downward balancing is almost exclusively provided from gas fired generators in Hungary, this observation suggests that Hungarian generators offer decremental energy with substantial markdowns from marginal cost.

In the literature several modeling approaches have been used to predict the performance of electricity markets. One such approach is the supply function equilibrium model, originally developed by Klemperer and Meyer [2]. They show that when firms face uncertain demand they prefer to set supply function rather than compete in quantities or prices. The supply function equilibrium model has been extensively used in the empirical literature for analyzing electricity markets. Many studies including Rudkevich, Duckworth, and Rosen [3] and Baldick, Grant, and Kahn [4] compare estimates of market power with that predicted by the theory using marginal cost estimates, while others,

This is an Open Access article distributed in accordance with the Creative Commons Attribution Non Commercial (CC-BY-NC-ND 4.0) license, which permits others to copy or share the article, provided original work is properly cited and that this is not done for commercial purposes. Users may not remix, transform, or build upon the material and may not distribute the modified material (http://creativecommons.org/licenses/by-nc/4.0/) 
including Wolak [5] and Bosco, Parisio, and Pelagatti [6], retrieve marginal cost functions and price-cost margins from bid data assuming optimal bidding.

The other major modeling approach in the analysis of electricity markets is the multi-unit auction theory. This approach was first applied by von der Fehr and Harbord [7] and subsequently developed further by Anwar [8], Crespo [9] and Fabra, von der Fehr, and Harbord [1]. This approach assumes that generators submit stepfunction bids to a multi-unit auction. It is argued that the discrete bid space better reflects the institutional reality of electricity markets. Indeed, in real electricity auctions it is common to place a restriction on the number of bids a bidder can make. Several studies have used the multi-unit auction model to empirically analyze the generators' bidding behavior in the England and Wales wholesale electricity market. For example, Wolfram [10] shows that larger suppliers bids more than smaller suppliers for similar units and also that suppliers bid larger markups for units being higher up in the merit order. Crawford, Crespo, and Tauchen [11] find evidence for asymmetric bidding behavior between the price-setter and the nonprice setters which corresponds to the prediction of the (uniform pricing) multi-unit auction model with capacity constrained bidders.

While day-ahead electricity markets have attracted a large body of empirical research, much less attention has been paid to the reserve capacity and balancing energy markets. An exception is the balancing energy market of the Texas electricity market, which has been examined by a number of researchers. Niu [12] compares the observed balancing energy prices to that emerging from the supply function equilibrium model. The equilibrium prices are calculated in a linear function supply model using estimated cost data. The results of the analysis show that the price data fit the theoretical model quite well for the upward balancing market, but there is a large discrepancy for the downward balancing market. The analysis by Sioshani and Oran [13] is also based on the comparison of the actual supply curves and the optimal bidding curves in the Texas balancing energy market. Their results show that the supply function model produces a good prediction of bidding behavior of power plants only in the case of the largest generators. Heim and Götz [14] examines whether the drastic price increase in the German power reserve market has been solely driven by increased costs. The authors provide statistical evidence that market price has been manipulated by the two largest generators. The authors suggest that the pivotal position of the power plants and the pay-as-bid pricing rule applied in the
German market have been the main reasons for this output.

\section{Market design for the Hungarian balancing energy market}

The balancing energy market is a market where the TSO can buy or sell energy (the so-called balancing energy) at short notice. The balancing energy is used to cover the differences between electricity generation and consumption after the closing of the intraday electricity market. This paper focuses on the market for secondary balancing energy. ${ }^{1}$

In Hungary, the procurement of balancing energy consists of two phases: the "capacity-selection" phase and the "capacity-ordering" phase. In the first phase, the TSO selects the power plants that are held in reserve to be available for real-time balancing. This is performed through the so called reserve capacity auctions. In Hungary, reserve capacity auctions are held once a year and upward and downward regulation reserves are procured as separate services. In the reserve auction, the TSO runs separate sections for each day of the following year and selects the winners in each section on the basis of the capacity fee bids. The TSO awards market maker contracts to the successful bidders. The contract specifies the days of the year on which the service is to be provided and amount of reserve to be delivered for each contracted day. It also specifies the capacity fees to be paid to the provider for each delivery day. The capacity remuneration is based on the accepted bids. The capacity fee can be seen as an option price paid by the TSO to the generator for keeping the capacity available and not being used in other ways. However, the price at which the generator is prepared to buy or sell excess energy from/to the TSO (i.e. the "strike price" of the option) is only determined in the second phase of the procurement process: in the balancing energy auction. ${ }^{2}$ The balancing energy auction is held daily with 24 time segments each of one hour. Bidders in the balancing energy auction can be grouped into two categories: contracted parties and non-contracted parties. On a given day the contracted parties are those who previously won market maker contract for that day. They are obliged to make energy price bids up to the contracted capacity at each hour of the day. The energy price bid cannot be lower than the minimum bidding price

\footnotetext{
${ }^{1}$ Tertiary control power is rarely used in Hungary.

${ }^{2}$ However, the contract specifies a minimum bidding price (maximum bidding price) in case of the decremental (incremental) energy.
} 
L. Paizs
Electricity Pricing and Market Power: Evidence from the Hungarian Balancing Energy Market

determined in the contract. In addition to contracted suppliers all technically qualified suppliers can bid into the balancing energy auction at short notice. They get remunerated if called. However they do not receive any capacity fee. The energy price bids are used by the TSO to determine the dispatch order of generators in each hour of the following day. The reserve capacities are called upon according to their energy price bids when imbalances occur. The remuneration is based on the payas-bid settlement rule.

\section{Theoretical framework}

I draw on the discriminatory multi-unit auction model in Fabra, von der Fehr, and Harbord [1] to inform the empirical analysis. The authors of this paper analyze a game-theoretic model in which two single-unit firms with asymmetric capacities and costs compete to supply the market. They assume that each firm has a single unit with constant marginal cost up to capacity. Firms must submit a single price offer for their entire capacity, which may not be higher than the reserve price set by the auctioneer. Further, it is assumed that firms face a market demand that is perfectly inelastic. They derive the equilibrium strategies in this game for different demand realizations. They show that under a certain threshold the game has a unique Nash-equilibrium in pure strategies, while above this threshold it has a unique Nash-equilibrium in mixed strategies. They also provide comparative static results which show how bidding strategies change with changes in the model parameters. In particular, they demonstrate that in high-demand realizations price competition is more intense when there are more bidders, capacities are more symmetrically distributed, and the reserve price is lower.

There are a number of reasons why the theoretical model described in [1] is thought to be an appropriate framework for analyzing the Hungarian balancing market. First, the auction mechanism adopted in the Hungarian balancing market is similar to the one considered in [1]. Most importantly, it is a distinguishing feature of the Hungarian balancing energy auction that firms must submit a single price offer for their entire reserve capacity. Similarly to the auction model in [1], the price bid is constrained by a reserve price preset in the contract. Second, the market structure modeled in [1] is very representative of the Hungarian balancing energy market. As said before, the auction market for downward balancing is characterized by high market concentration. In fact, in 2012, there were 160 days on which only two single-unit generators were bidding for decremental energy.

Although Fabra, von der Fehr, and Harbord [1] obtain their results for a reverse auction, one can easily derive similar results for an ordinary auction. In doing so, I formulated the following hypotheses:

1. The number of bidders has a positive impact on the average decremental energy price (calculated as a simple average of all submitted hourly price bids).

2. A more equal distribution of capacities among bidders has a positive impact on the average decremental energy price.

3. An increase in capacity asymmetry initially increases and the decreases the price dispersion (measured by the difference between the highest and lowest price bids).

\section{Market characteristics}

\section{Power generation sector of Hungary}

Total electricity consumption in Hungary reached 40 TWh, in 2012. Nuclear produced $46 \%$ of domestic generation while natural gas provided $28 \%$, coal $20 \%$ and renewables $6 \%$. Two-thirds of power generation came from two large base-load plants: Paks (nuclear-based) and Matra (lignite-based). Hungary has $10 \mathrm{GW}$ of installed generation capacity, which exceeds the country's peak load measured in $2012(6.5 \mathrm{GW})$ by about 50 percent. Hungary's electricity system is interconnected with all but one of its neighbors with a large capacity compared to the size of the market. In 2012, net import totaled $8 \mathrm{TWh}$, or 20 percent of total electricity supply.

\section{Market for decremental balancing energy}

In 2012, a total of nine power plants participated in the down-regulation market in Hungary. All but one power plants providing balancing power were natural gas-based. There are two main factors that explain the dominance of natural gas plants in the balancing power market. Firstly, Hungary has no hydroelectric power plants. Second, the nuclear and lignite base-load plants (Paks and Matra) do not participate in the balancing power market.

In most European countries gas-fired generators have been struggling with poor economic conditions since 2011. Due to a combination of low electricity and high natural gas prices producer margins have fallen drastically. In early 2012 the average spark spread dropped below zero in many European electricity markets. Given the importance of gas-fired generators in providing balancing power in Hungary, next we review the relationship between the competitiveness of gas-fired plants and their incentives to provide balancing power.

Down-regulating reserves are spinning reserves 
because generation can be reduced only at units that are already producing energy. Therefore, the cost of reserve capacity depends on the spread between wholesale price and variable cost. If the marginal generation cost of a power plant is below the electricity price at the wholesale market, then the supplier would run the plant at full capacity. Hence, in such periods the cost of providing negative reserve for real-time balancing is zero. If the marginal generation cost of a power plant exceeds the electricity price at the wholesale market than the cost of keeping negative reserve at the plant equals the loss the supplier incurs from generating and selling electricity. To provide negative control power, the production level of the plant must exceed its minimal technical load by the amount of reserve power delivered. The higher is the difference between the marginal cost of the plant and the wholesale electricity price, the higher is the price that the supplier will charge for keeping reserve power. ${ }^{3}$

From the above discussion it follows that there is an inverse relationship between the electricity price at the wholesale market and the availability and price of negative reserve power. At times when wholesale prices are low and fewer generating units are scheduled to operate, it costs more for the TSO to procure the necessary amount of reserve.

Over 2012, the average spot price for base-load power was $51.5 \mathrm{EUR} / \mathrm{MWh}$ and the spot price for peak-load was 61.3 EUR/MWh in the Hungarian Power Exchange (HUPX). Under realistic efficiency parameters and 2012 natural gas prices, an average CCGT plants had variable cost of around 80-90 EUR/MWh. These figures suggest that power companies run their gas-fired plants only in hours in which they were contracted to provide reserve power to the TSO and could recover their loss in their capacity fee. This also implies that in the daily balancing energy auctions the TSO only received bids from the contracted parties, since other providers did not operate their gas-fired units due to weak market conditions.

3 This illustration assumes that the marginal cost of production is constant.

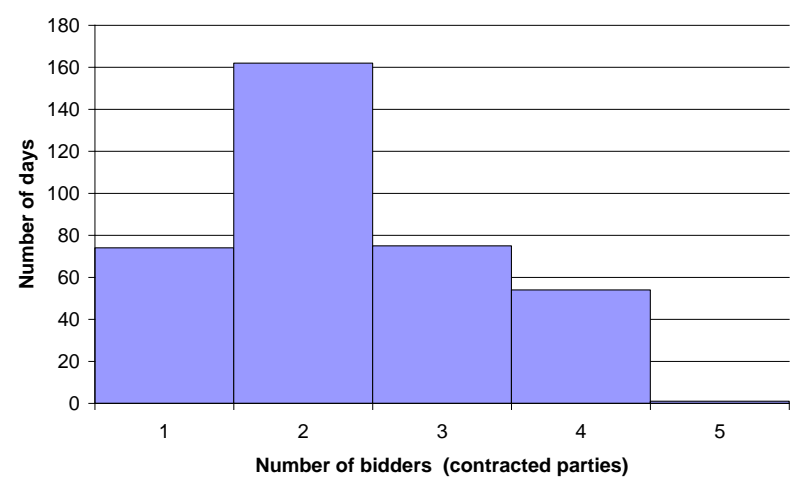

Fig. 1 Distribution of the numbers of bidders in the daily balancing energy auctions (2012)

Figure 2 shows the seasonal pattern of supply of and demand for decremental energy. As seen, the expected amount of negative balancing energy tends to be higher in the heating season. It is also seen that the TSO attempts to maintain the supply-demand balance and reserve more down-regulating capacity in the winter months. As a result, there is no clear seasonal pattern in the supplydemand balance. The expected demand balance seems to be constant throughout the year.

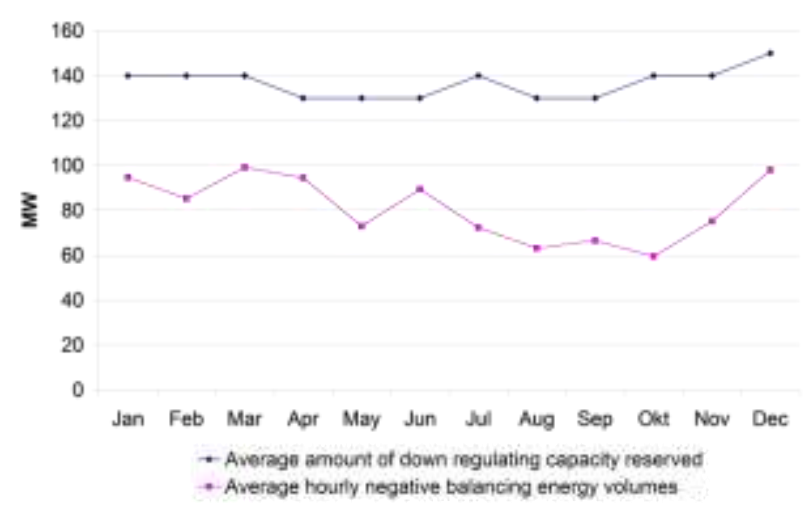

Fig. 2 Supply-demand balance in the decremental energy market (2012)

\section{Empirical analysis}

My aim is to assess the effect of market structure on prices in the auction market for downward balancing energy. Since the winning bidders of the reserve capacity auctions are released on the TSO's webpage, I have accurate data for those bidders in the daily balancing energy auctions who were contractually obliged to participate, i.e. market makers. ${ }^{4}$ These data allow me to

${ }^{4}$ Although the data about the winning bids are released in an anonymized form on the TSO's webpage, the identity of the bidders can be easily revealed on the basis of the load gradients (i.e. the rate of change of nominal output in a given timeframe) 
characterize the market structure of the balancing energy auctions, if it is assumed that other suppliers than market makers made no bids. Unfortunately, with respect to the outcome of the balancing energy auctions, only the simple average of all submitted energy price bids, as well as the maximum and minimum energy price bids are published. These dataset does not allow for an assessment of individual bidding strategies. However, using the large variation in the identity, number and capacity share distribution of bidders across auctions held on different days I can analyze the impact of market structure on price levels and dispersion.

\section{Empirical investigation and results}

To test Hypotheses 1-2, I estimate the following regression model:

$$
B_{t}=\alpha+\beta H H I_{t}^{a s y m}+\tau D_{t}+\chi X_{t}+\delta Y_{t}+\varepsilon_{t},
$$

where $B_{t}=\frac{1}{6} \sum_{h=1}^{6} \frac{1}{n_{t}} \sum_{i=1}^{n_{t}} b_{t h i}$ is the average bid over all bidders and over all hours between 0AM and 6AM in day $t, H H I^{a s y m}$ is a measure of capacity asymmetry, $D_{t}$ is a set of dummies each representing the same group of bidders, $X_{t}$ is a vector of general control variables (e.g. spot gas price), and $Y_{t}$ is a vector of control variables applying to CHP plants only (e.g. the outside temperature).

The reason why I use the daily averages of hourly bids is that the market structure variables vary only across days.

My data cover only the bids from the contracted parties (market makers). As argued before, we have a good reason to believe that other firms than contracted parties did not submit bids into the balancing energy market in most of the hours of the year. This was assumed on the basis that the low electricity prices on the wholesale market in 2012 made gas-fired generation unprofitable. (Therefore gas-fired power plants were online only in those days when they had a contract with the TSO to provide balancing power and could recover their loss in the capacity payment.) This assumption surely holds for the off-peak hours when prices are the lowest. Hence, only the bids submitted during the hours 0-6 AM are used for the empirical analysis.

The bidder group dummies indicate if the same group of generators participates in the auction. They are used to remove the time-invariant unobserved heterogeneity between power generators (such as difference in production costs).

Following Lijesen and van de Vort [15], I define a measure of capacity share inequality based on the Herfindahl Hirschman Index (HHI). The HHI can be decomposed into two components:

$$
\begin{gathered}
H H I=\sum_{i=1}^{N}\left(s_{i}\right)^{2}=\frac{1}{N}+N \frac{\sum_{i=1}^{N}\left(s_{i}-1 / N\right)^{2}}{N}= \\
\frac{1}{N}+N \sigma^{2}=H H I^{N}+H H I^{\text {asym }}
\end{gathered}
$$

(2)

where $H H I^{N}$ and $H H I^{a s y m}$ measure, respectively, the effects of the number of suppliers and market share inequality on market concentration. Since the former effect is captured by the bidding group dummies, I included only $\mathrm{HHI}^{a s y m}$ in Eq. (1).

Table 1 reports the results of the estimation of Eq. (1). There are four columns of results: in the first two, the OLS (Ordinary Least Squares) method is used, while in the last two, the WLS (Weighted Least Squares) method is applied.

The key variables of interest are the $H H I^{\text {asym }}$ and the group dummies. The coefficient of the $H H I^{a s y m}$ is statistically significant and of negative value in all models presented in Table 1. These results confirm the theoretical finding that an increase in the asymmetry in capacity shares leads to lower prices. The estimates of coefficients on the group dummies indicate that increasing the number of bidders from two to three leads to stronger competition (higher bids). However, competition among four bidders on average resulted in lower prices (weaker competition) than competition between three bidders. I suspect that this unexpected result has to do with the behavior of CHP plants. Other studies reported that CHP plants tend to underprice their decremental offers because they have strong disincentives to adjust their output [12]. Since the cases when one or more CHP plants participated in the balancing market overlap with the cases when four bidders took part in the auction, the relatively low price associated with the auctions with four bidders are likely to be explained by the presence of CHP plants among the bidders. 
Table 1: Estimates for average decremental energy price (2012)

\begin{tabular}{|c|c|c|c|c|}
\hline Model & (1) & (2) & (3) & (4) \\
\hline Method: & OLS & OLS & WLS & WLS \\
\hline C & $\begin{array}{l}-2.608^{*} \\
(1.454)\end{array}$ & $\begin{array}{r}-11.075 * * * \\
(2.428)\end{array}$ & $\begin{array}{r}-2.761^{* * *} \\
(0.877)\end{array}$ & $\begin{array}{r}-12.455 * * * \\
(1.363)\end{array}$ \\
\hline $\mathrm{HHI}^{359 \mathrm{~m}}$ & $\begin{array}{r}-2,820^{*} \\
(1.615)\end{array}$ & $\begin{array}{r}-2.904^{* *} \\
(1.310)\end{array}$ & $\begin{array}{r}-3.024 * t \\
(1.235)\end{array}$ & $\begin{array}{r}-2.211^{* *} \\
(1.094)\end{array}$ \\
\hline D_TwoBuyers1 & $\begin{array}{r}1.627 * 0 \\
(0.638)\end{array}$ & $\begin{array}{r}1.677 * * * \\
(0.516)\end{array}$ & $\begin{array}{r}-0.289 \\
(0.574)\end{array}$ & $\begin{array}{r}0.502 \\
(0.515)\end{array}$ \\
\hline D_TwoBuyers2 & $\begin{array}{r}0.498 \\
(0.525)\end{array}$ & $\begin{array}{r}0.526 \\
(0.544)\end{array}$ & $\begin{array}{r}0.510 \\
(0.536)\end{array}$ & $\begin{array}{r}0.091 \\
(0.475)\end{array}$ \\
\hline D_TwoBuyers3 & $\begin{array}{r}1.310^{* * *} \\
(0.423)\end{array}$ & $\begin{array}{r}1.377 * * * \\
(0.418)\end{array}$ & $\begin{array}{r}1,158 * 4 * \\
(0.380)\end{array}$ & $\begin{array}{r}1.238^{4 * *} \\
(0.335)\end{array}$ \\
\hline D_ThreeBuyers! & $\begin{array}{r}2.923 * k 4 \\
(0.307)\end{array}$ & $\begin{array}{r}3.091 * 3 * \\
(0.299)\end{array}$ & $\begin{array}{r}1.693^{* * *} \\
(0.314)\end{array}$ & $\begin{array}{r}2.577^{* * *} \\
(0.295)\end{array}$ \\
\hline D_ThreeBuyers 2 & $\begin{array}{r}1.667 * * * \\
(0.374)\end{array}$ & $\begin{array}{r}2.050 * * * \\
(0.352)\end{array}$ & $\begin{array}{r}1.110^{* * * *} \\
(0.416)\end{array}$ & $\begin{array}{r}1.901 * * * \\
(0.378)\end{array}$ \\
\hline D_FourBuyers 1 & $\begin{array}{r}1.796 * * 4 \\
(0.284)\end{array}$ & $\begin{array}{r}1.815 * * * \\
(0.271)\end{array}$ & $\begin{array}{l}0.611^{*} \\
(0.313)\end{array}$ & $\begin{array}{r}1.201^{* * * *} \\
(0.285)\end{array}$ \\
\hline D_FourBuyers2 & $\begin{array}{r}-0.346 \\
(0.278)\end{array}$ & $\begin{array}{r}-0.381 \\
(0.268)\end{array}$ & $\begin{array}{r}-1.780^{* * *} \\
(0.320)\end{array}$ & $\begin{array}{r}-1.093^{* 4 *} \\
(0.293)\end{array}$ \\
\hline D_FourBuyers 3 & $\begin{array}{r}0.671 \cdots \cdots \\
(0.125)\end{array}$ & $\begin{array}{r}1.601^{* \cdots *} \\
(0.243)\end{array}$ & $\begin{array}{r}-0.362 \\
(0.455)\end{array}$ & $\begin{array}{r}1.138 * * . * \\
(0.437)\end{array}$ \\
\hline TIF & $\begin{array}{r}0.417^{* *} \\
(0.182)\end{array}$ & $\begin{array}{r}0.192 \\
(0.120)\end{array}$ & $\begin{array}{r}0.674 * * * \\
(0.098)\end{array}$ & $\begin{array}{r}0.392 * * * \\
(0.092)\end{array}$ \\
\hline Outside temperature & $\begin{array}{r}0.088^{* *} \\
(0.039)\end{array}$ & $\begin{array}{r}0.108^{* *} \\
(0.043)\end{array}$ & $\begin{array}{r}-0.105 * * * \\
(0.029)\end{array}$ & $\begin{array}{r}0.042 \\
(0.031)\end{array}$ \\
\hline Total regulating capacity & & $\begin{array}{r}0.073 * 4 * \\
(0.018)\end{array}$ & & $\begin{array}{r}0.077^{* 4 * *} \\
(0.009)\end{array}$ \\
\hline $\operatorname{AR}(1)$ & $\begin{array}{r}0.712^{* * * *} \\
(0,068) \\
\end{array}$ & $\begin{array}{r}0.484 * * * \\
(0.072) \\
\end{array}$ & & \\
\hline Observations: & 268 & 268 & 269 & 269 \\
\hline R-squared: & 0.86 & 0.87 & 0.80 & 0.85 \\
\hline \multicolumn{5}{|c|}{$\begin{array}{l}\text { Notes: Dependent variable: the daily average of decremental } \\
\text { energy price bids (HUF/kWh); } \\
\text { heteroskedastic-consistent standard errors are in parentheses for } \\
\text { OLS models; } \\
\text { number of bidders is used as weights for WLS models; } \\
\text { significant at } 10 \%, * * \text { significant at } 5 \%, * * * \text { significant at } 1 \%\end{array}$} \\
\hline
\end{tabular}

The TTF stands for the spot price of natural gas. As expected, the coefficient of this variable has a positive sign. (The higher the cost of natural gas, the more can be gained from reducing output.)

To test Hypotheses 3, I estimate the following regression model:

$$
\begin{aligned}
& \left(B_{t}^{\max }-B_{t}^{\min }\right)=\alpha+\beta_{1} H H I_{t}^{\text {asym }}+ \\
& \beta_{2} H H I_{t}^{\text {asym }} \cdot H H I_{t}^{\text {asym }}+\tau D_{t}+\chi X_{t}+\delta Y_{t}+\varepsilon_{t}
\end{aligned}
$$

where $\quad B_{t}^{\max }=\frac{1}{6} \sum_{h=1}^{6} \operatorname{Max}\left(b_{t h 1} ; b_{t h 2} ; \ldots ; b_{t h n_{t}}\right) \quad$ is the hourly average maximum bid in hours 1-6 in day $t$,

$$
B_{t}^{\min }=\frac{1}{6} \sum_{h=1}^{6} \operatorname{Min}\left(b_{t h 1} ; b_{t h 2} ; \ldots ; b_{t h n_{t}}\right)
$$

is the hourly average minimum bid in hours 1-6 in day t. This specification follows from the hypothesis that the impact of capacity asymmetry may be non-monotonic. I add
$\mathrm{HHI}_{t}^{\text {asym }}$ squared to equation (3) to account for this possibility.

Table 2 reports the results of the estimation of Eq. (3).

\begin{tabular}{|c|c|c|c|c|}
\hline $\begin{array}{l}\text { Eq Name: } \\
\text { Method: }\end{array}$ & $\begin{array}{l}\text { (1) } \\
\text { OLS }\end{array}$ & $\begin{array}{l}\text { (2) } \\
\text { OLS }\end{array}$ & $\begin{array}{c}\text { (3) } \\
\text { WLS }\end{array}$ & $\begin{array}{c}\text { (4) } \\
\text { WLS }\end{array}$ \\
\hline C & $\begin{array}{r}-0.261 \\
(6.033)\end{array}$ & $\begin{array}{r}5.727 \\
(5.707)\end{array}$ & $\begin{array}{r}-0.872 \\
(3.265)\end{array}$ & $\begin{array}{r}2.664 \\
(3.234)\end{array}$ \\
\hline $\mathrm{HHI}^{\text {anya }}$ & $\begin{array}{l}-3.265 \\
(2.639)\end{array}$ & $\begin{array}{r}21.222 * 44 \\
(7.549)\end{array}$ & $\begin{array}{l}-2.427 \\
(2.619)\end{array}$ & $\begin{array}{r}22.855 * 4 * 4 \\
(6.016)\end{array}$ \\
\hline 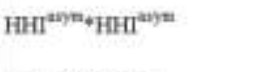 & & $\begin{array}{r}-63.491 \\
(16.662)\end{array}$ & & $\begin{array}{r}-66.473 * 40 \\
(14.364)\end{array}$ \\
\hline D_TwoBuyers1 & $\begin{array}{r}2.410^{k *} \\
(1.075)\end{array}$ & $\begin{array}{r}0.919 \\
(1.320)\end{array}$ & $\begin{array}{r}-0.360 \\
(1.232)\end{array}$ & $\begin{array}{r}-1.190 \\
(1.199)\end{array}$ \\
\hline D_TwoBuyers2 & $\begin{array}{r}0.032 \\
(1.100)\end{array}$ & $\begin{array}{r}0.254 \\
(1.243)\end{array}$ & $\begin{array}{r}-0.389 \\
(1.139)\end{array}$ & $\begin{array}{r}-0.313 \\
(1.096)\end{array}$ \\
\hline D_TwoBuyers3 & $\begin{array}{r}0.519 \\
(0.911)\end{array}$ & $\begin{array}{r}-0.591 \\
(1.046)\end{array}$ & $\begin{array}{r}0.264 \\
(0.803)\end{array}$ & $\begin{array}{r}-1.140 \\
(0.830)\end{array}$ \\
\hline D_ThreeBuyers1 & $\begin{array}{r}0.892 \\
(0.637)\end{array}$ & $\begin{array}{r}-0.814 \\
(0.923)\end{array}$ & $\begin{array}{r}-0.200 \\
(0.707)\end{array}$ & $\begin{array}{r}-1.832^{4 *} \\
(0.766)\end{array}$ \\
\hline D_ThreeBuyers2 & $\begin{array}{r}0.500 \\
(0.763)\end{array}$ & $\begin{array}{r}-1.826 \\
(1.137)\end{array}$ & $\begin{array}{r}-0.257 \\
(0.905)\end{array}$ & $\begin{array}{r}-2.529 * * \\
(1.000)\end{array}$ \\
\hline D_FourBuyers1 & $\begin{array}{r}2.786^{* * * *} \\
(0.592)\end{array}$ & $\begin{array}{r}2.393^{4 * 4} \\
(0.658)\end{array}$ & $\begin{array}{r}1.113 \\
(0.681)\end{array}$ & $\begin{array}{r}0,901 \\
(0.657)\end{array}$ \\
\hline D_FourBuyers? & $\begin{array}{r}1.88604 * * \\
(0.616)\end{array}$ & $\begin{array}{l}1.297^{\circ} \\
(0.691)\end{array}$ & $\begin{array}{r}0.485 \\
(0.702)\end{array}$ & $\begin{array}{r}0.312 \\
(0.677)\end{array}$ \\
\hline D_FourBuyers 3 & $\begin{array}{r}0.865 \\
(0.537)\end{array}$ & $\begin{array}{r}0.221 \\
(0.593)\end{array}$ & $\begin{array}{r}-0.059 \\
(1.047)\end{array}$ & $\begin{array}{r}-0.352 \\
(1.009)\end{array}$ \\
\hline TIF & $\begin{array}{c}0.523^{k \mathrm{k}} \\
(0.265)\end{array}$ & $\begin{array}{r}0.342 \\
(0.230)\end{array}$ & $\begin{array}{r}0.298 \\
(0.221)\end{array}$ & $\begin{array}{r}0.186 \\
(0.214)\end{array}$ \\
\hline Outside tenperature & $\begin{array}{l}0.191^{* *} \\
(0.080)\end{array}$ & $\begin{array}{r}0.009 \\
(0.090)\end{array}$ & $\begin{array}{l}-0.067 \\
(0.074)\end{array}$ & $\begin{array}{r}-0.166^{* *} \\
(0.075)\end{array}$ \\
\hline Total regulating capacity & $\begin{array}{r}-0.017 \\
(0.042)\end{array}$ & $\begin{array}{r}-0,043 \\
(0.039)\end{array}$ & $\begin{array}{r}0.017 \\
(0.021)\end{array}$ & $\begin{array}{r}0.001 \\
(0.021)\end{array}$ \\
\hline $\operatorname{AR}(1)$ & $\begin{array}{r}0.513+\cdots \\
(0.091)\end{array}$ & $\begin{array}{r}0.443 * 0 * \\
(0.085)\end{array}$ & & \\
\hline Observations: & 268 & 268 & 269 & 269 \\
\hline R-squared: & 0.50 & 0.54 & 0.36 & 0.41 \\
\hline
\end{tabular}

Table 2: Estimates for price dispersion in the decremental energy market (2012)

Notes: Dependent variable: the difference between the maximum and minimum decremental energy price bids (HUF/kWh);

heteroskedastic-consistent standard errors are in parentheses for OLS models;

number of bidders is used as weights for WLS models;

significant at $10 \%, * *$ significant at $5 \%$, *** significant at $1 \%$

The empirical results are consistent with the theoretical predication. The parameter values of $\beta_{1}$ and $\beta_{2}$ imply that price dispersion is increasing at $H H I^{a s y m}$ levels below 0.17 and decreasing at $H H I^{\text {asym }}$ levels of 0.17 and higher.

\section{Conclusion}

This paper assesses the effect of market structure on prices in the auction market for downward balancing energy in Hungary. It shows that fewer bidders, less equal distribution of reserved capacities among bidders, and the presence of CHP plants lead to less competitive pricing. These results suggests that in an environment in which the TSO can only rely on the contracted parties to provide daily balancing services it should pay more attention to 
L. Paizs
Electricity Pricing and Market Power: Evidence from the Hungarian Balancing Energy Market

the sufficiency of the number of reserve providers and their market shares in the contracting phase (i.e. in the reserve capacity auction).

\section{References}

[1] Fabra, N, von der Fehr, N.-H.M. and D. Harbord "Designing electricity auctions." RAND Journal of Economics 37(1), pp 23-46. 2006.

[2] Klemperer, P.D. and M.A. Meyer "Supply function equilibria in oligopoly under uncertainty." Econometrica 57(6), pp 1243-1277. 1989.

[3] Rudkevich, A., Duckworth, M., Rosen, R. "Modelling electricity pricing in a deregulated generation industry: the potential for oligopoly pricing in poolco." The Energy Journal 19(3), pp 19-48. 1998.

[4] Baldick, R., Grant, R., Kahn, E. "Theory and application of linear supply function equilibrium in electricity markets." Journal of Regulatory Economics 25(2), pp 143-167. 2004.

[5] Wolak, F.A. "Identification and estimation of cost functions using observed bid data: an application to electricity markets" In: Dewatripont, M., Hansen, L.P., Turnovsky, S.J. (Eds.) Advances in Economics and Econometrics: Theory and Applications. Eighth World Congress, Volume II. pp 133-169, Cambridge University Press, New York, 2003.

[6] Bosco, B., L. Parisio and M. Pelagatti "Strategic Bidding in Vertically Integrated Power Markets with an Application to the Italian Electricity Auctions." Energy Economics 34, pp 2046-2057. 2012.

[7] Fehr, N-H. von der and D. Harbord "Spot Market Competition in the UK Electricity Industry." Economic Journal 103, pp 531-546. 1993.

[8] Anwar, A.W. "The case for a discriminatory pricing rule in competitive electricity pools." Mimeo, Department of Economics, Edinburgh University 1999.

[9] Crespo J. "Bidding asymmetries in multi-unit auctions: implications of bid functions equilibria in the british spot market for electricity." Ph.D Dissertation, University of North Carolina, 2001.

[10] Wolfram, C. D. "Strategic Bidding in a Multiunit Auction: An Empirical Analysis of Bids to Supply Electricity in England and Wales." RAND Journal of Economics. 29(4), pp 703-25. 1998.
[11] Crawford, G.S., Crespo, J., Tauchen, H. "Bidding asymmetries in multi-unit auctions: implications of bid function equilibria in the British spot market for electricity." International Journal of Industrial Organization 25, pp 1233-1268. 2007.

[12] Niu, H. "Models for electricity market efficiency and bidding strategy analysis." Ph.D. dissertation. Electrical and Computer Engineering Department, The University of Austin at Texas. 2005.

[13] Sioshansi, R., Oren, S. "How good are supply function equilibrium models: an empirical analysis of the ERCOT balancing market." Journal of Regulatory Economics 31, pp 1-35. 2007.

[14] Heim S, Götz G. "Do pay-as-bid auctions favor collusion? Evidence from Germany's market for reserve power." ZEW Discussion Paper No. 13-035. Mannheim. 2013. doi:10.2139/ssrn.2278873

[15] Lijesen, M., and Voort, M. "Market concentration and price dispersion; the role of asymmetric spatial competition." VU University of Amsterdam, Department of Spatial Economics. De Boelelaan. 2011. 